\title{
eLyra
}

REVISTA DA REDE INTERNACIONAL LYRACOMPOETICS

\section{Adília Lopes em edição colombiana, ilustrada por Sara Quijano, tradução de Alejando Giraldo Gil}

Como atrapar un pez

Sara Quijano, la ilustradora que acompañó con sus ilustraciones la edición de Tragaluz de Escribir un poema es como atrapar un pez, confirma ella sola algo que todos los lectores de Adília sabemos desde que la leemos: Adília es sencilla, cruda, sincera, cruel, descarnada, desnuda, íntima. Así fue como Sara dibujó a Adília: multiplicada en sus poemas, siempre la misma mujer en medio de versos que cuentan historias de otras mujeres. Apropiada de ese "cor-de-rosa", ese color rosado como de abuelita, pero descarnado a la vez como la sangre, Sara Quijano le dio rostro a las imágenes que Adília dibuja en sus versos, le dio arquitectura a los espacios propios que Adília construye en sus poemas. Recreó el mundo de Adília.

Quijano fue hábil en su representación del imaginario adiliano: escogió los colores a partir de pistas que entrevió en los poemas de Adília, pero más importante aún, entendió que ese imaginario debía tener un espacio, una geometría, una arquitectura. Así es que las ilustraciones de Quijano, además de representar una Adília de mil caras, a la Adília que se escribe a sí misma en su poesía, la representó hábilmente en sus espacios; espacios geométricos, escherianos incluso, pero de ella: íntimos, desentropiados. En apariencia bastos, pero con una atención minúscula, minuciosa incluso, al detalle. En ellos habitan los seres de Adília: los hombres, las tías, las mujeres perdidas, las lagartijas, la sangre, las comidas, los senos, el cuerpo, las cartas, los miles de rostros que asume la poetisa. Sus 
gatos, sus cucarachas. Quijano ilustra Adília siguiendo la misma intención poética, o al menos pretendiendo seguirla, con la que la poetisa escribe sus poemas: desde lo chico de la casa, desde los espacios reducidos, desde los seres pequeños que habitan en sus rincones. ¿Pero quién mejor para hablar de sus ilustraciones que la ilustradora misma? Sara misma nos dice:

La primera vez que abrí el libro de Adília me dispuse a perderme. Me acerqué página a página, me situé en su atmósfera -la sentí como propia, aunque sabía que ella estaba en Portugal y yo en Colombia o en Francia, donde vivo ahora-. Fue Adília misma la que me acercó al poema. Tengo la sospecha de que fue gracias a la sencillez de sus palabras y a su tono crudo (o cruel) y sincero, como el de un niño.

Pensé mucho en los colores, quería desnudar la ilustración. La intimidad fue mi base, quería mostrar la persona espontánea, la que se revela a menudo en la soledad; también los pequeños placeres, las tragedias cotidianas de las que no se habla y, a veces, se limitan a manifestarse en la forma de personitas fugaces que rondan en la cabeza.

Dibujé muchas veces a Adília. La vi multiplicada, sentada, desnuda, vestida, nunca corriendo, rosa. Era ella y era ella en otros. La sentía cerquita y la veía de lejos. Leía el libro y me miraba el cuerpo. Llené la bañera y saqué la barriga como una colina, me hundí los senos con el dedo. Tomé café y me acordé de las cucarachas de mi casa en Medellín.

Allá ya no hay cucarachas, fueron reemplazadas por las lagartijas. En el libro también hubo lugar para las lagartijas. 


\section{Escribir un poema es como atrapar un pez}

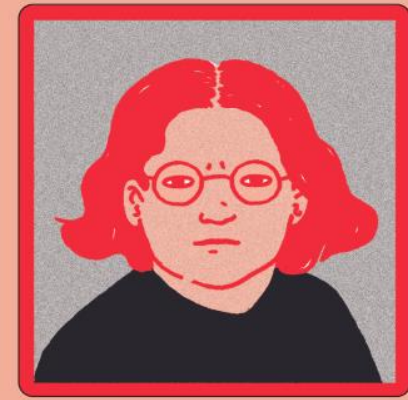

Adília Lopes

Traducción

Alejandro Giraldo Gil

Ilustración

Sara Quijano Sierra

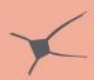




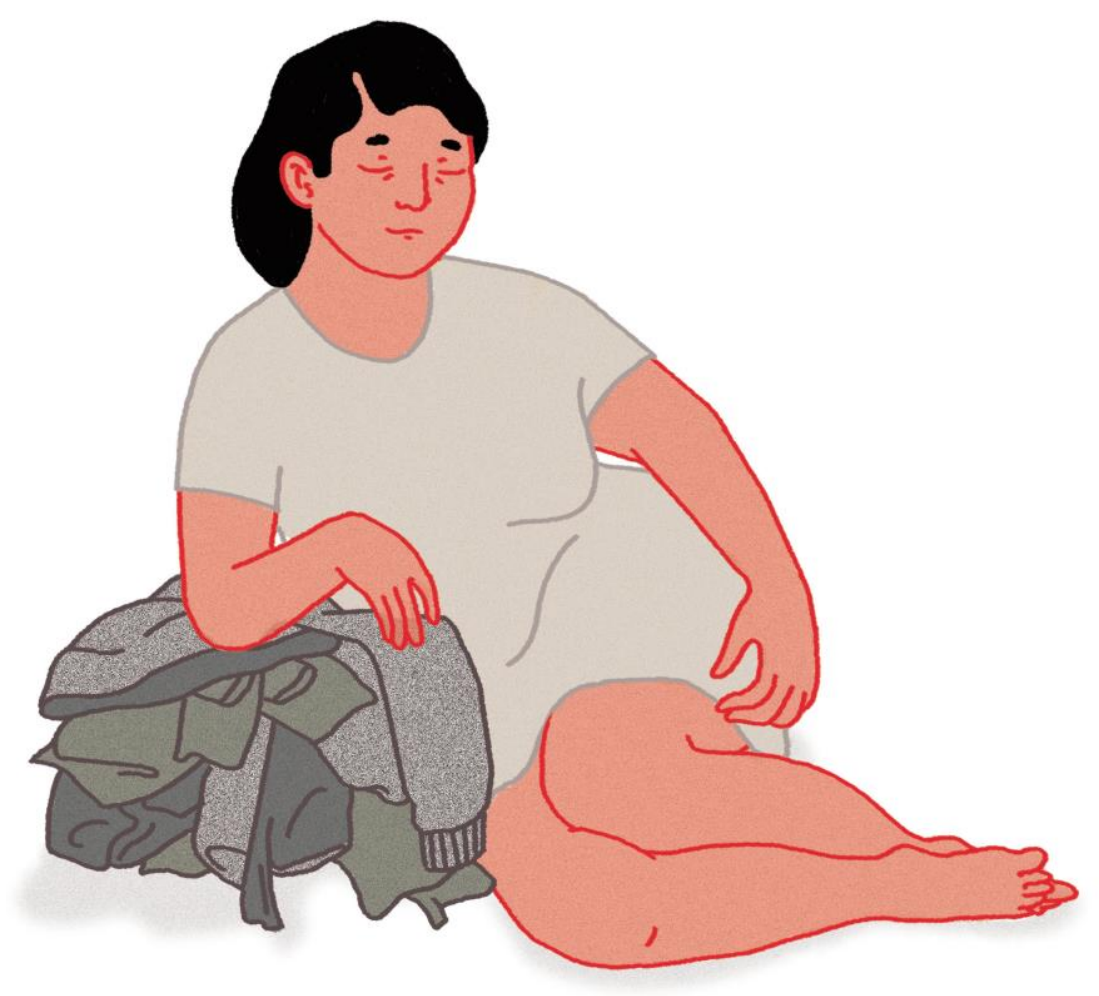

Ilustración tomada del libro: Escribir un poema es como atrapar un pez. 


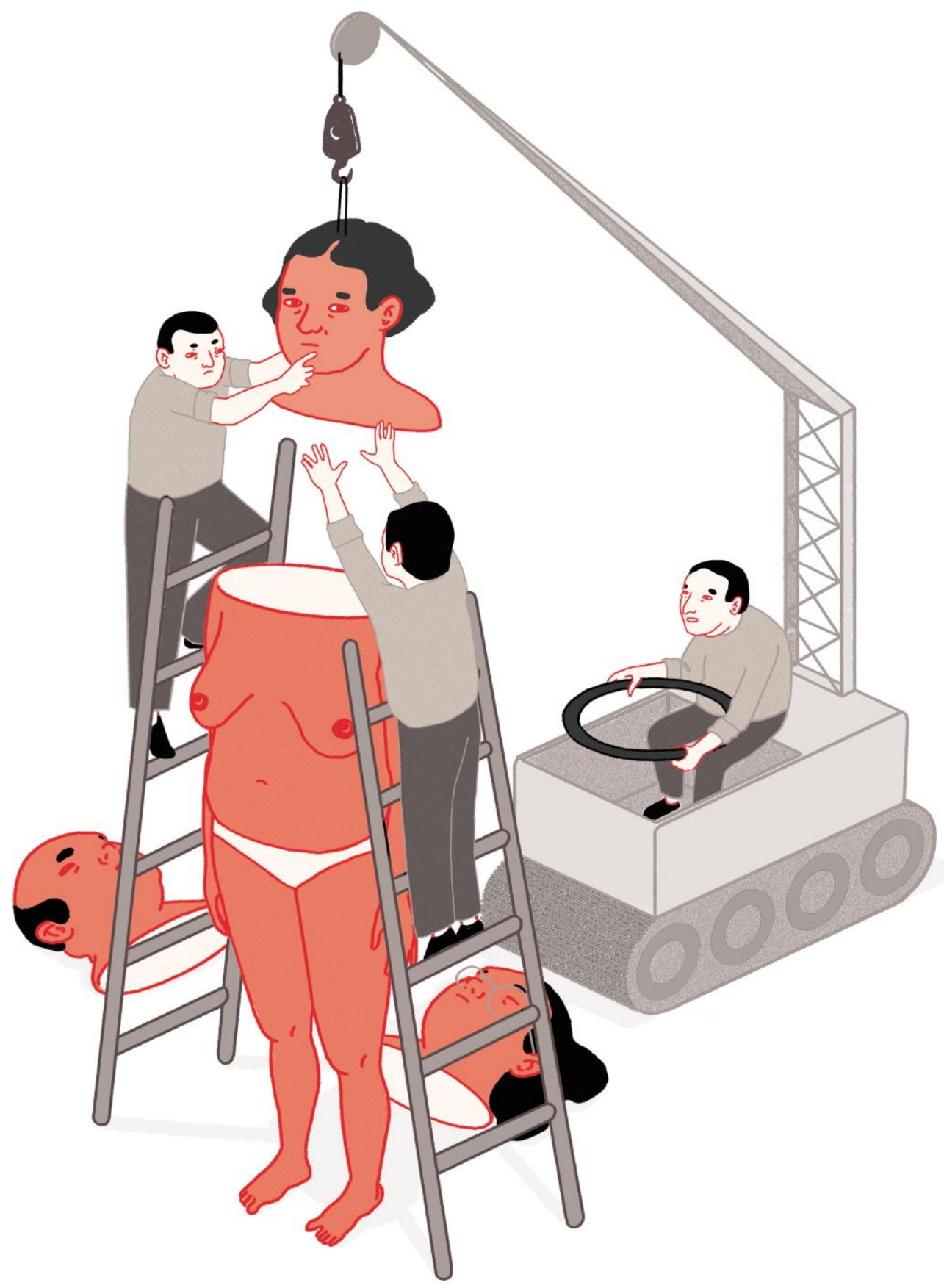




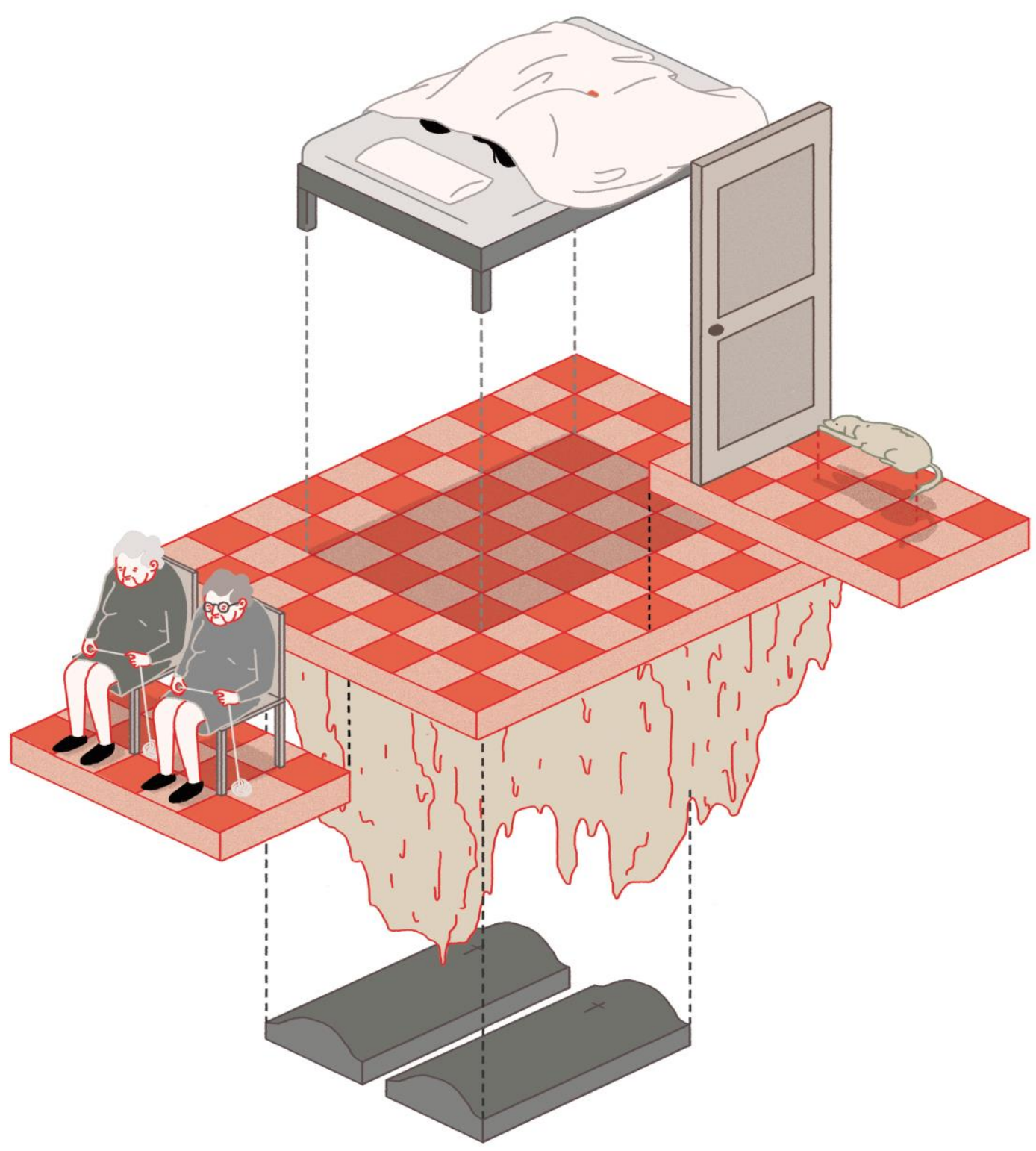

Ilustración tomada del libro: Escribir un poema es como atrapar un pez. 


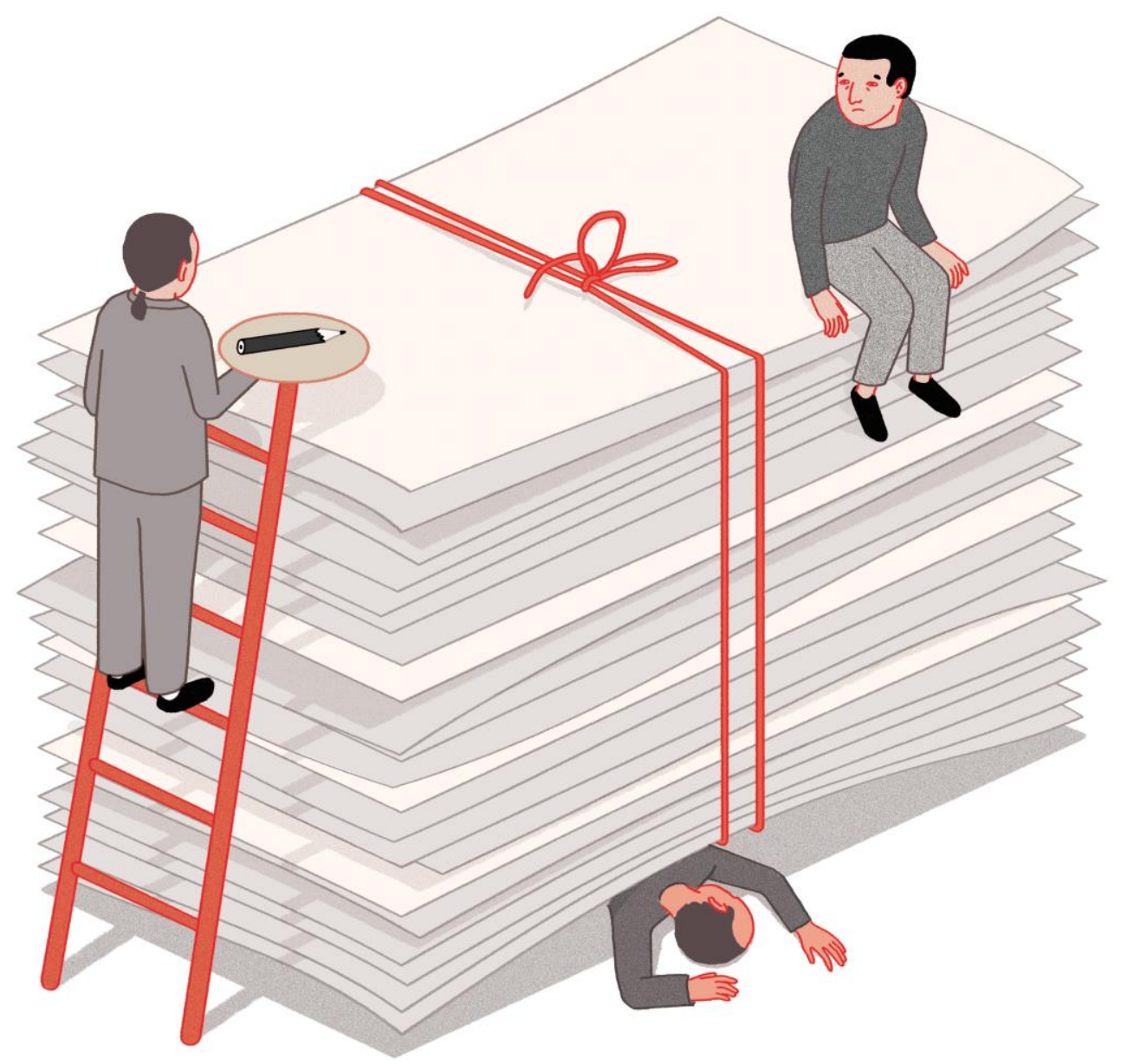

Ilustración tomada del libro: Escribir un poema es como atropar un pez 


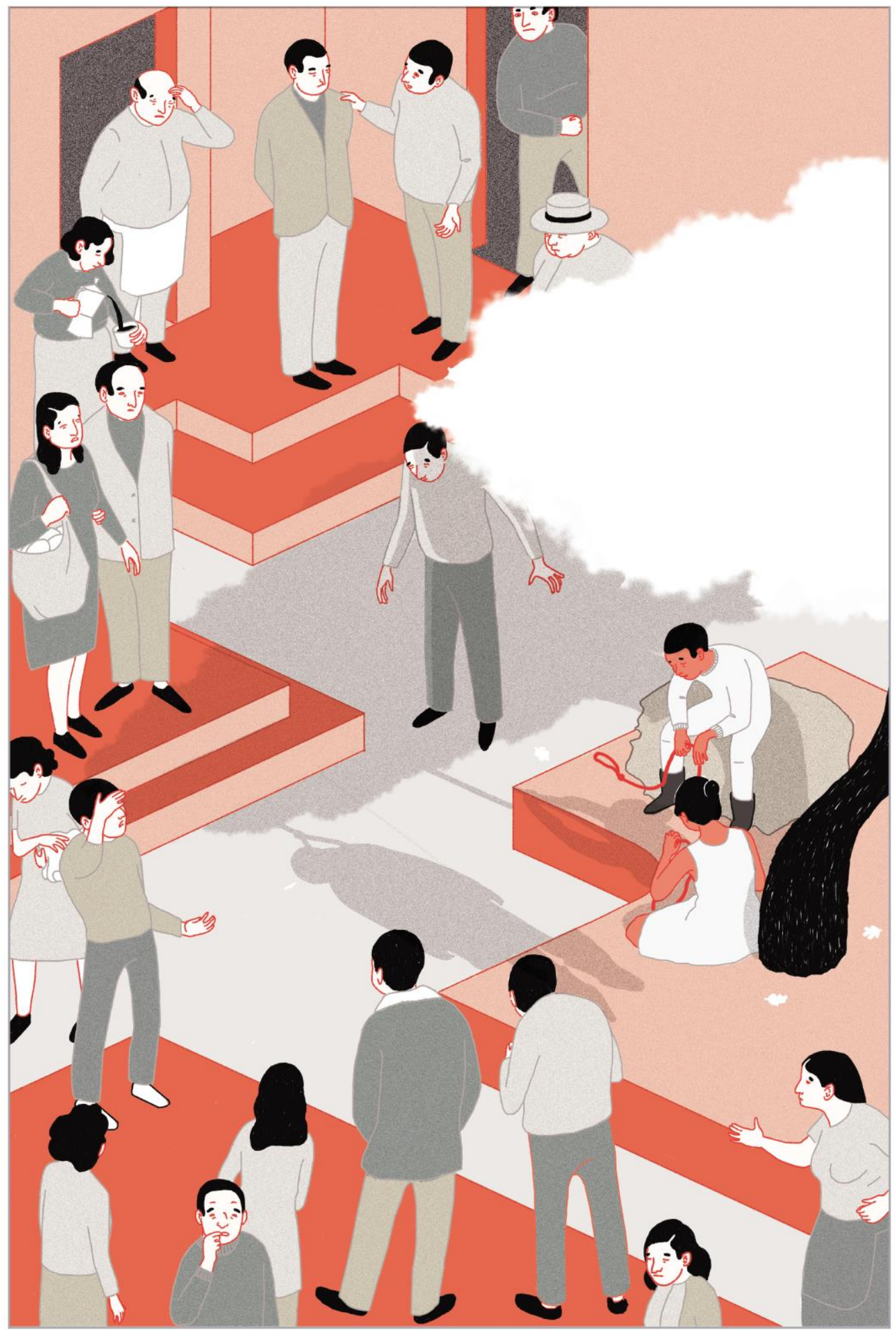

Ilustración tomada del libro: Escribir un poema es como atrapar un pez. 


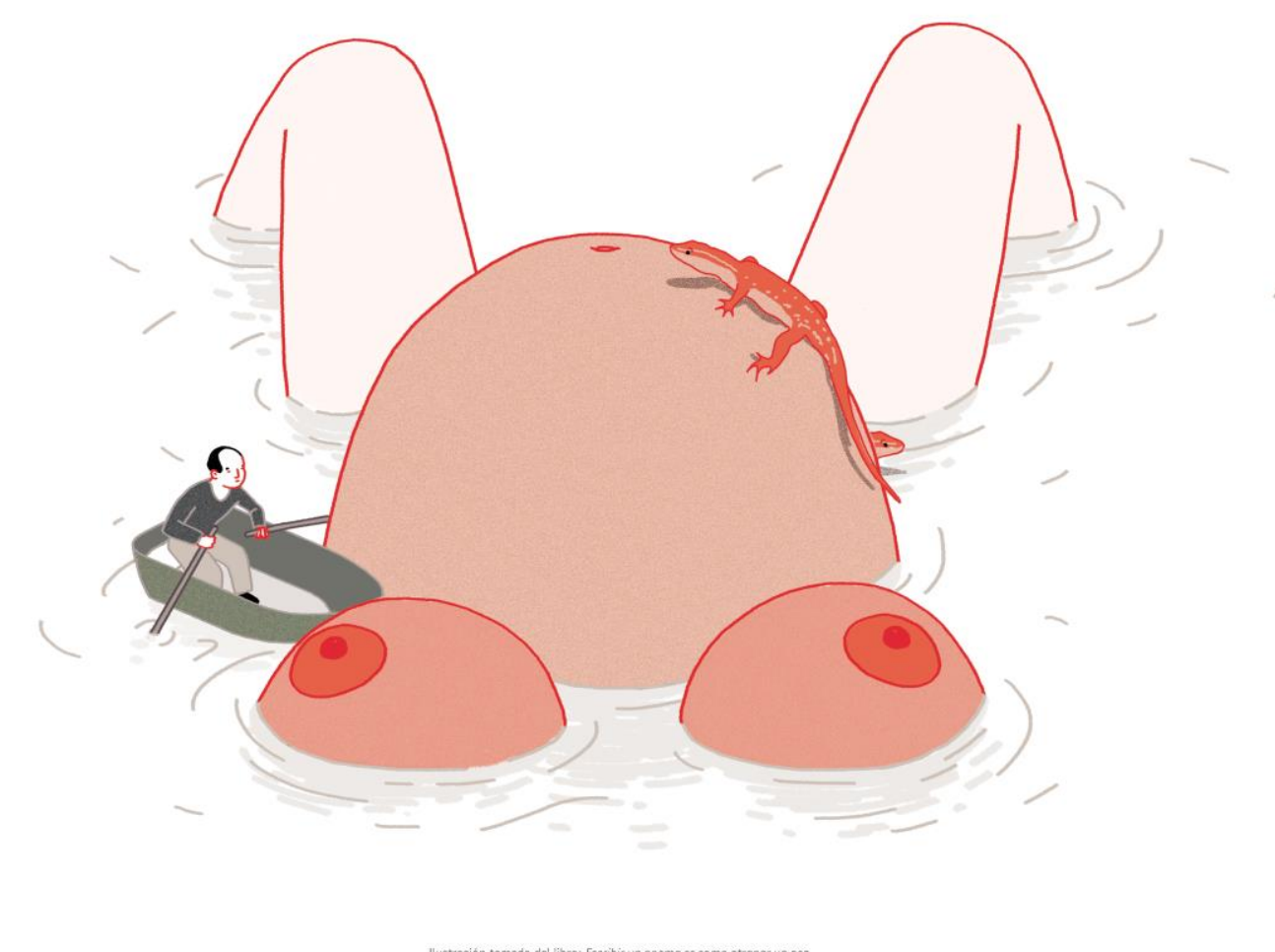

Ilustración tomada del libro: Escribir un poema es como otropar un pez 


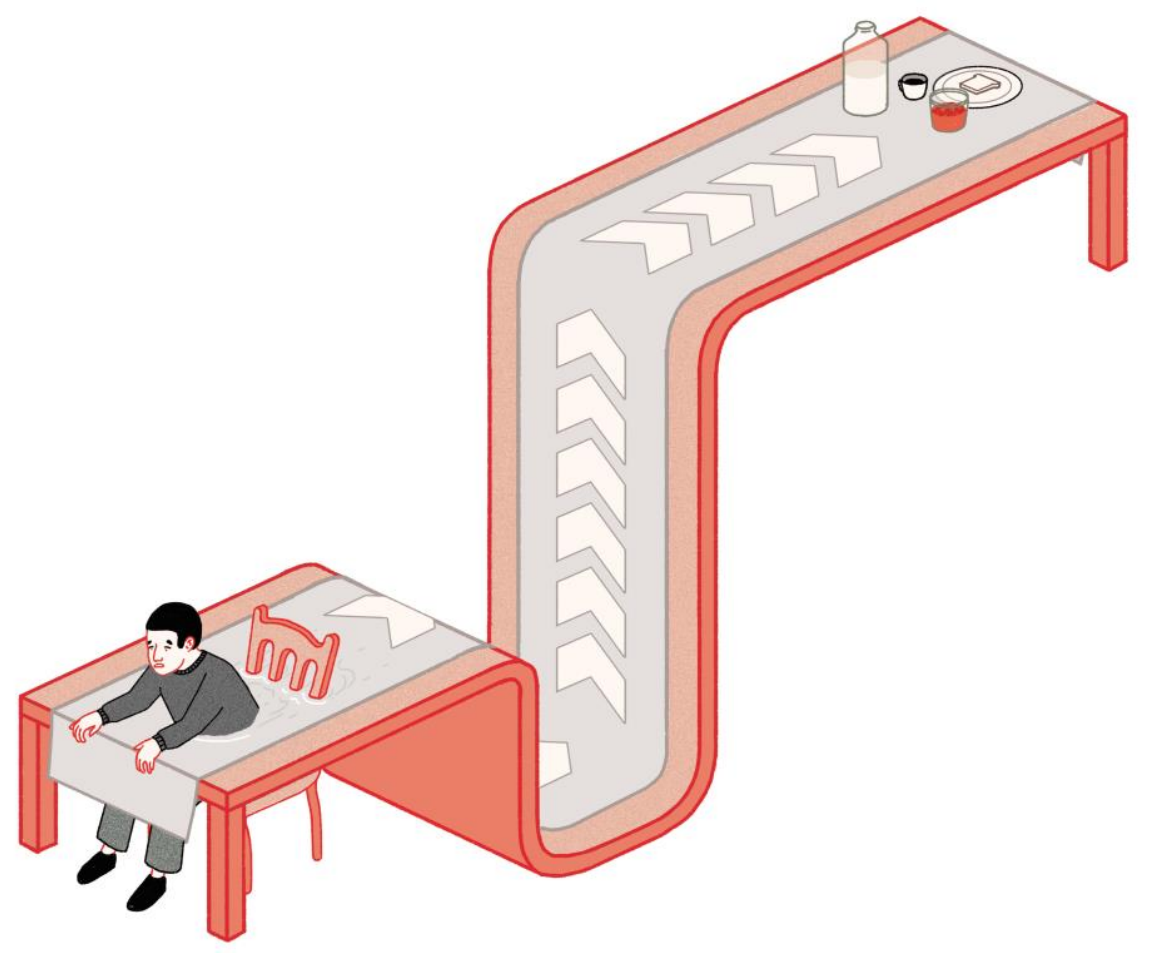

Ilustración tomada del libro: Escribir un poema es como otrapar un pez 


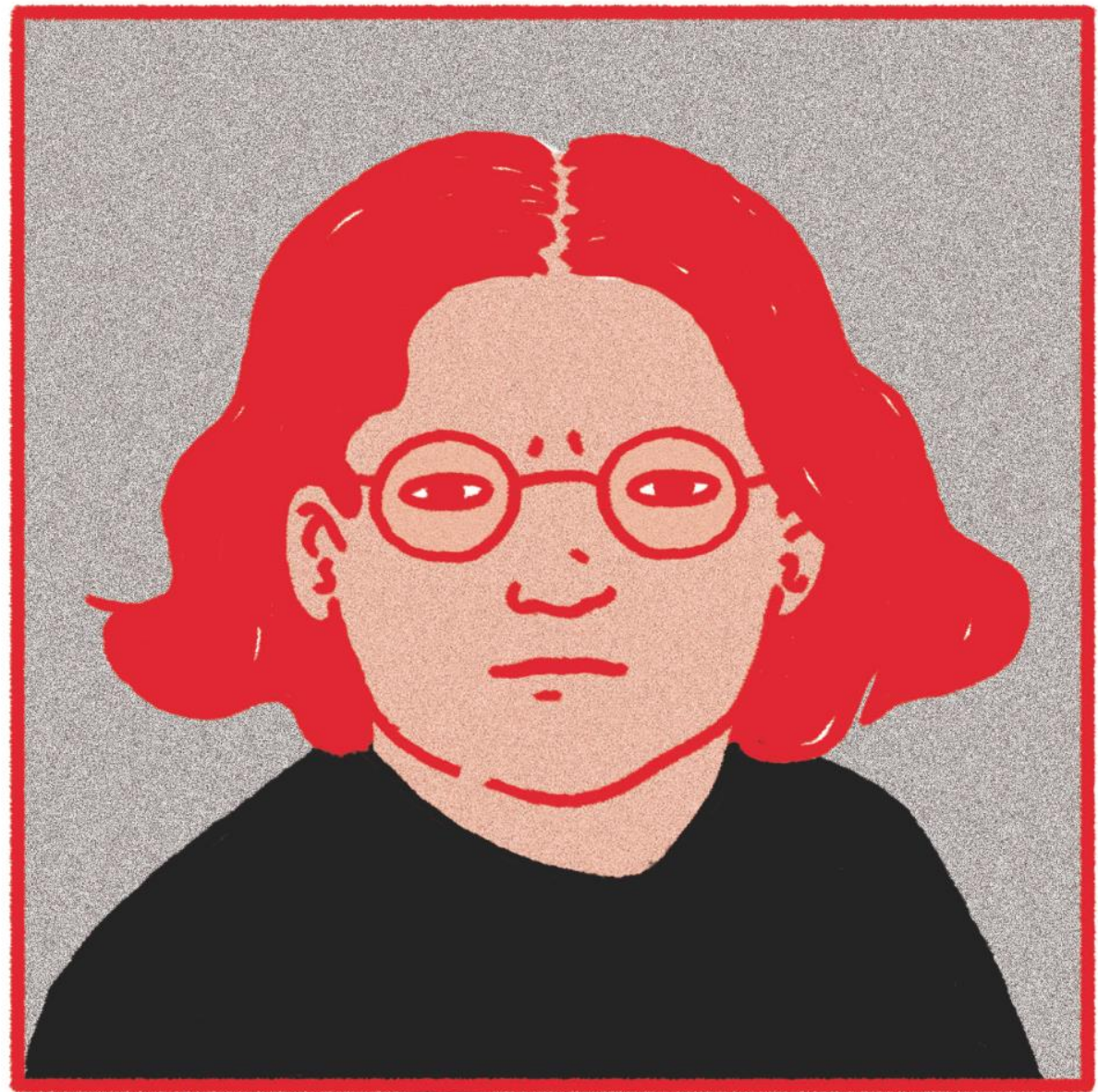

Ilustración tomada del libro: Escribir un poema es como atrapar un pez 

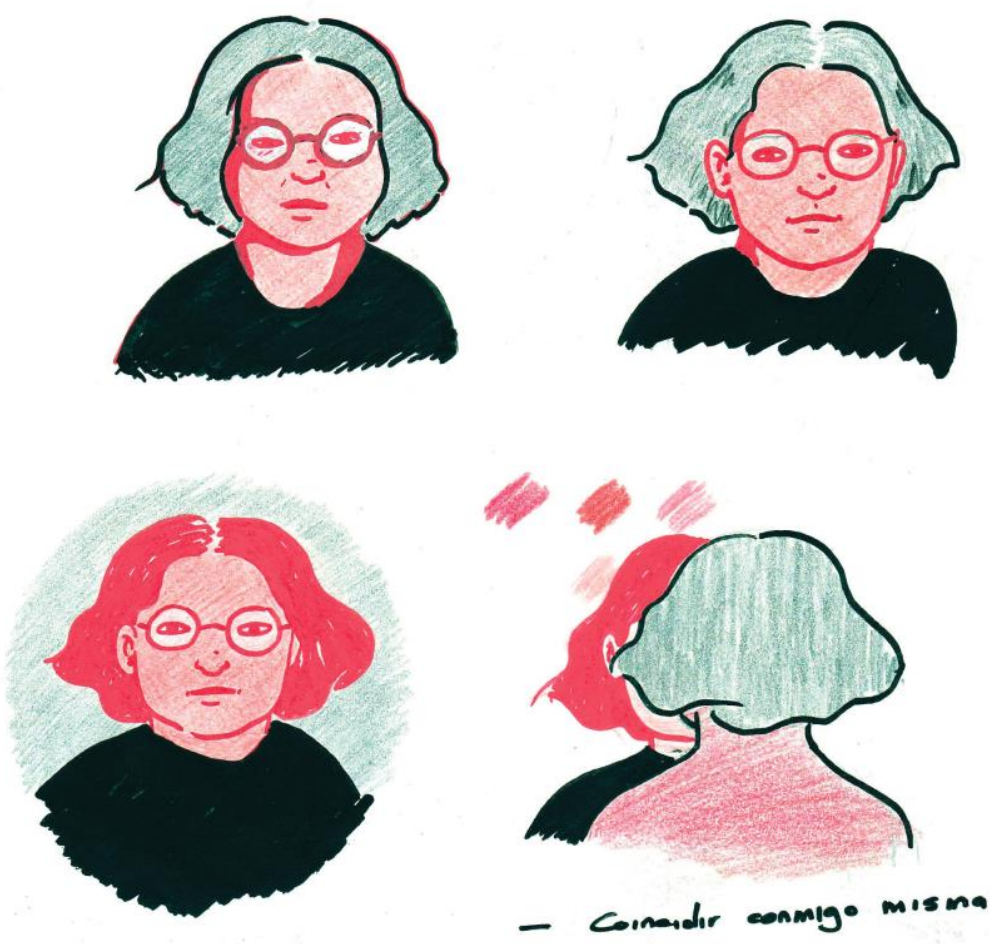


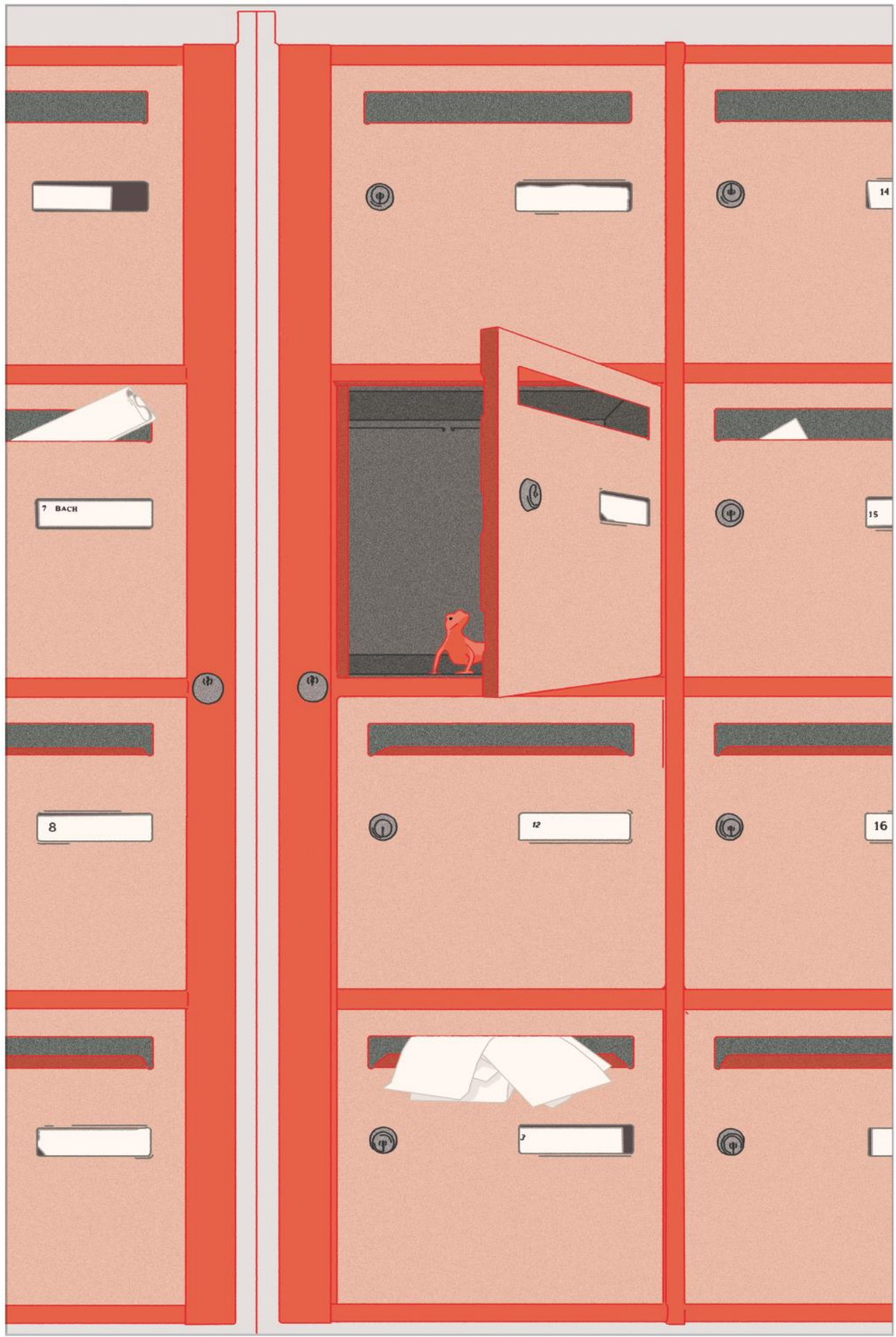

Ilustración tomada del libro: Escribir un poema es como atrapar un pez. 


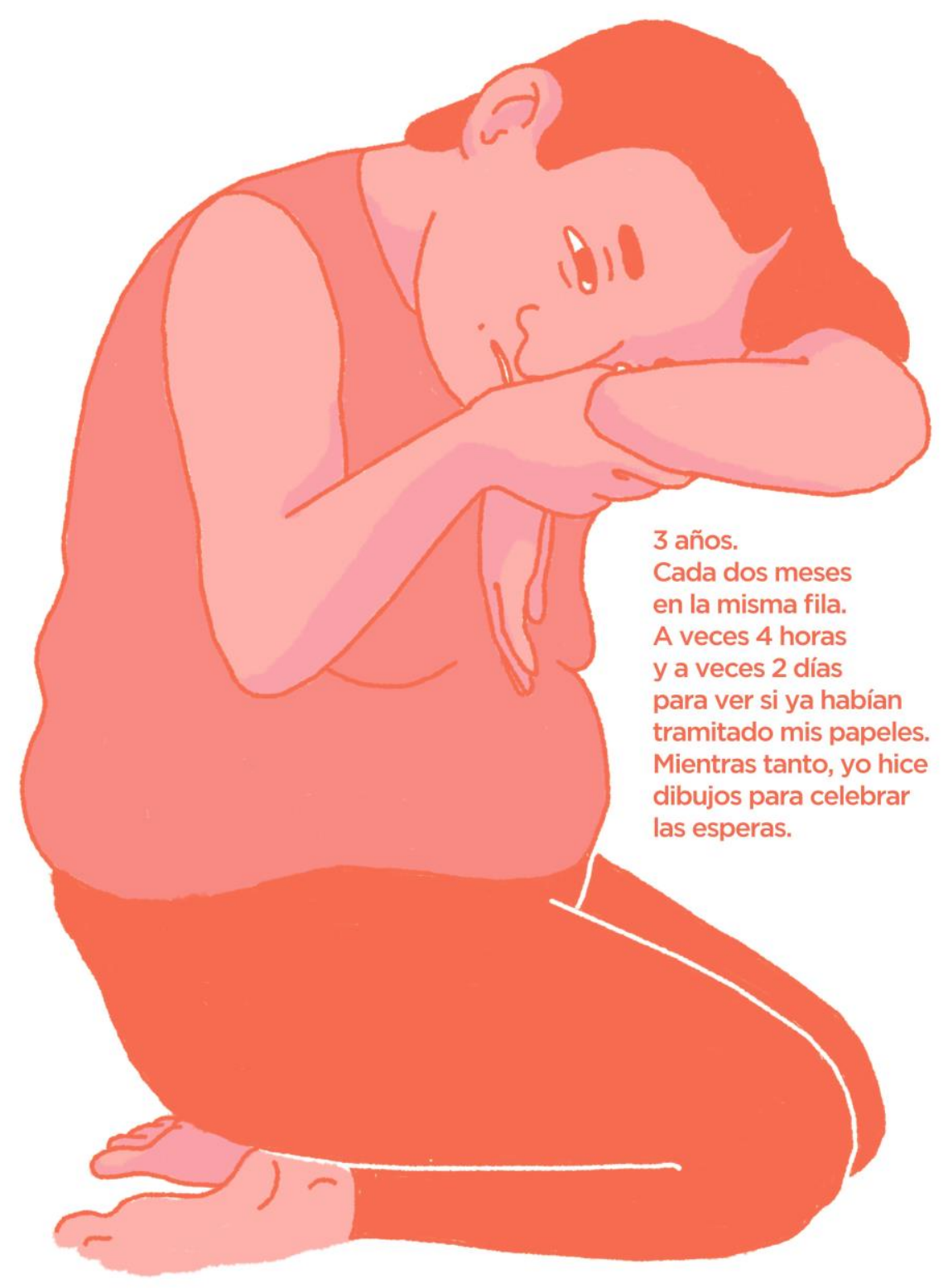



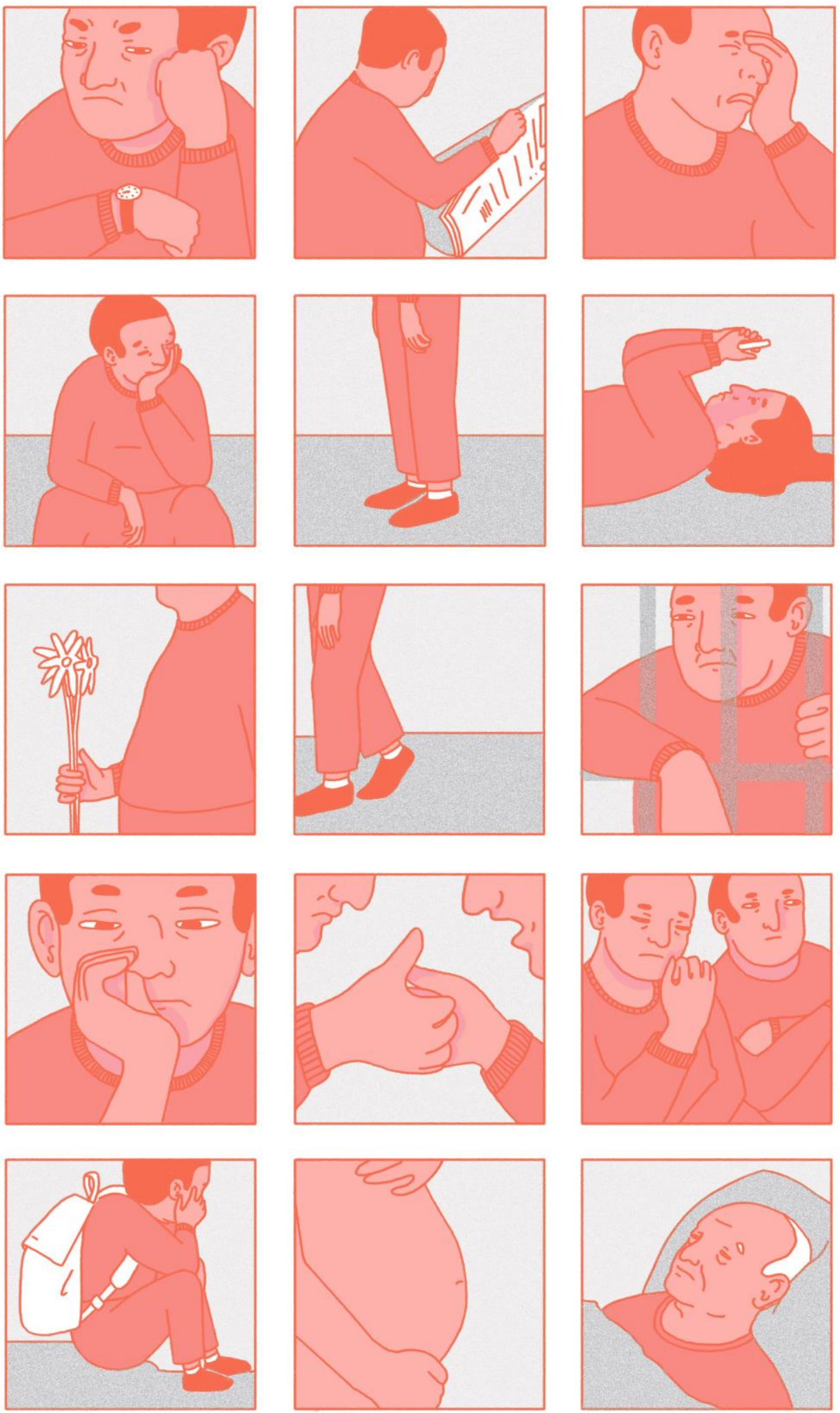

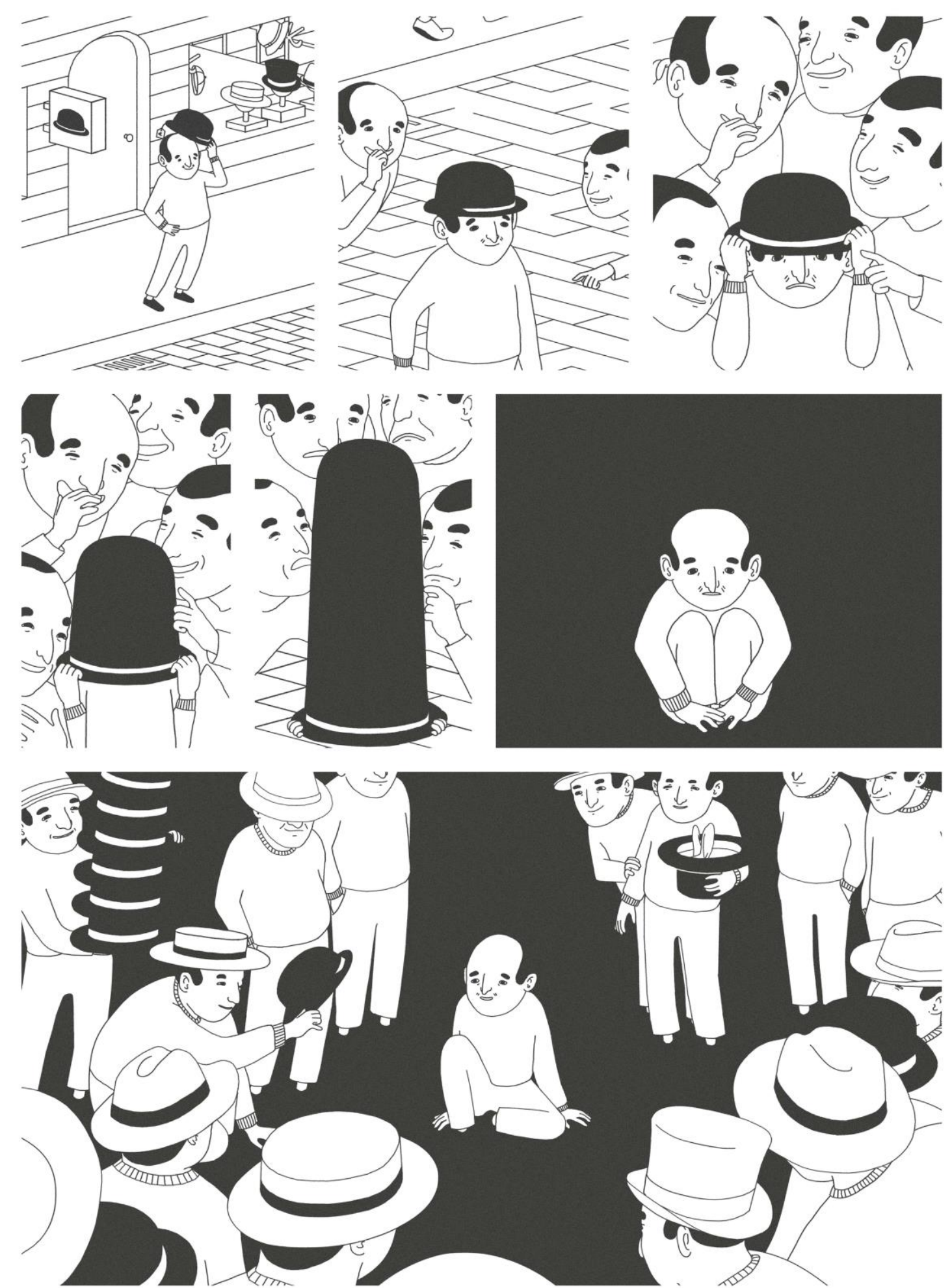

INTROSPECTION \#1 


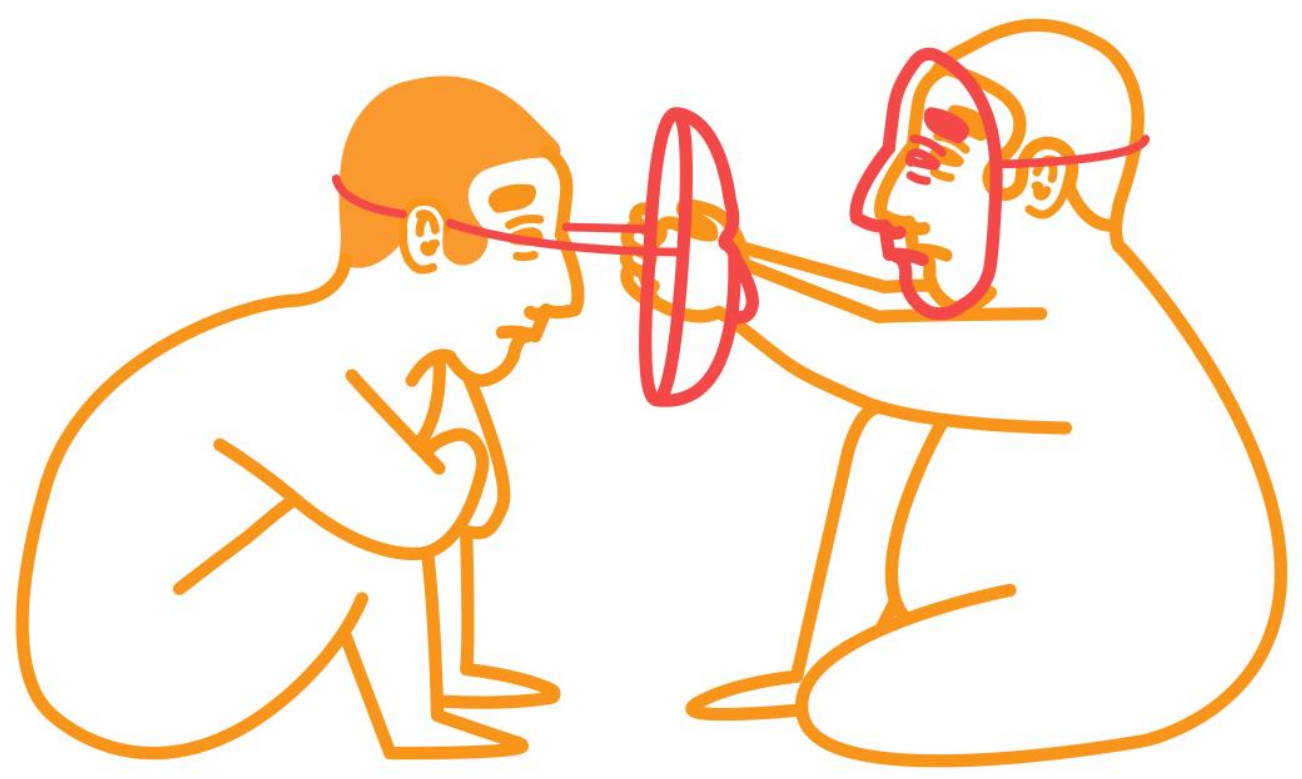




\section{Sara Quijano Sierra}

Nació en Medellín y estudió diseño de vestuario en la Universidad Pontificia Bolivariana. Actualmente vive en París. Desde alli participó del III Premio internacional Tragaluz de Ilustración en 2015. Su propuesta fue elegida entre más de 300 provenientes de 20 países. Gracias a este reconocimiento, ilustró el libro 'El cuarto del Tragaluz' de O. Henry, editado por Tragaluz a propósito de su aniversario número 10. En 2018 volvió a colaborar con la editorial para ilustrar el libro 'Escribir un poema es como atrapar un pez' de Adília López. 
Esta muestra reúne los dibujos originales de los libros 'Escribir un poema es como atrapar un pez' y 'El cuarto del Tragaluz', junto a otros proyectos que la ilustradora ha llevado a cabo de manera independiente. Tanto en unos como en otros los protagonistas son los trazos simples, el uso de pocas tintas y los espacios en blanco. Es así porque Sara Quijano es una gran intérprete de las cosas no dichas, de los silencios, de los sentidos ocultos. Su obra investiga, de una manera sutil, los misterios y revelaciones que trae consigo la poesía. 


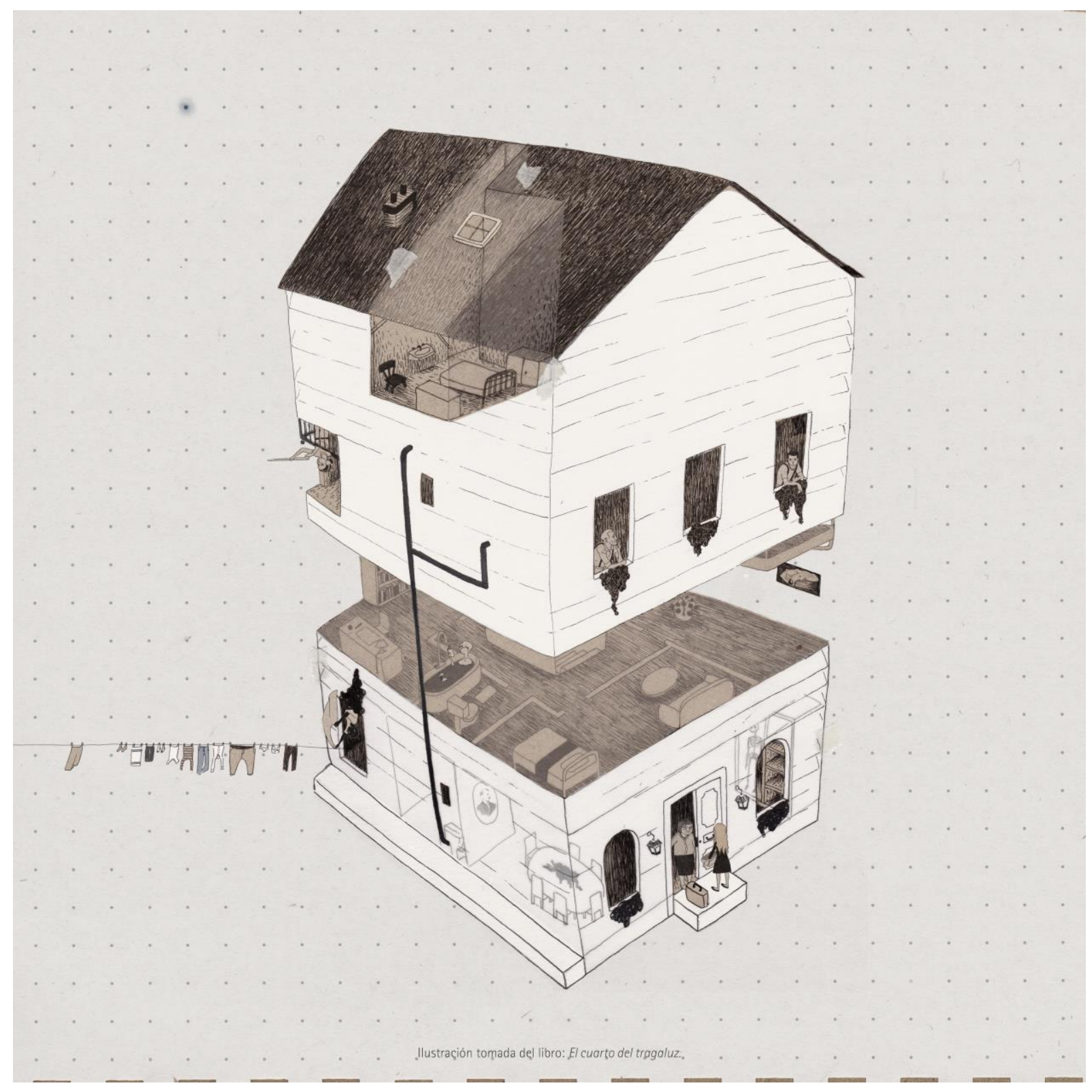




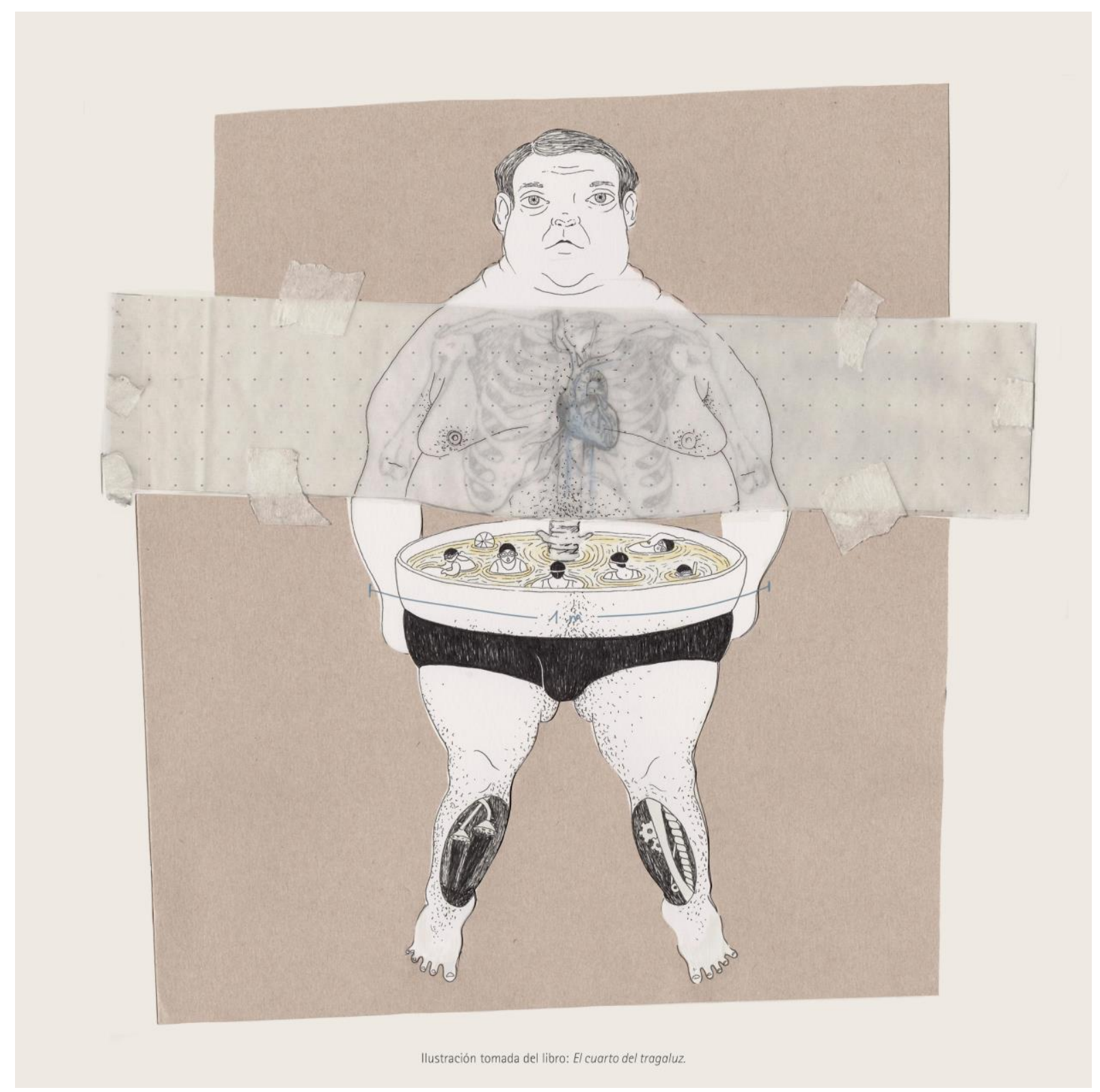




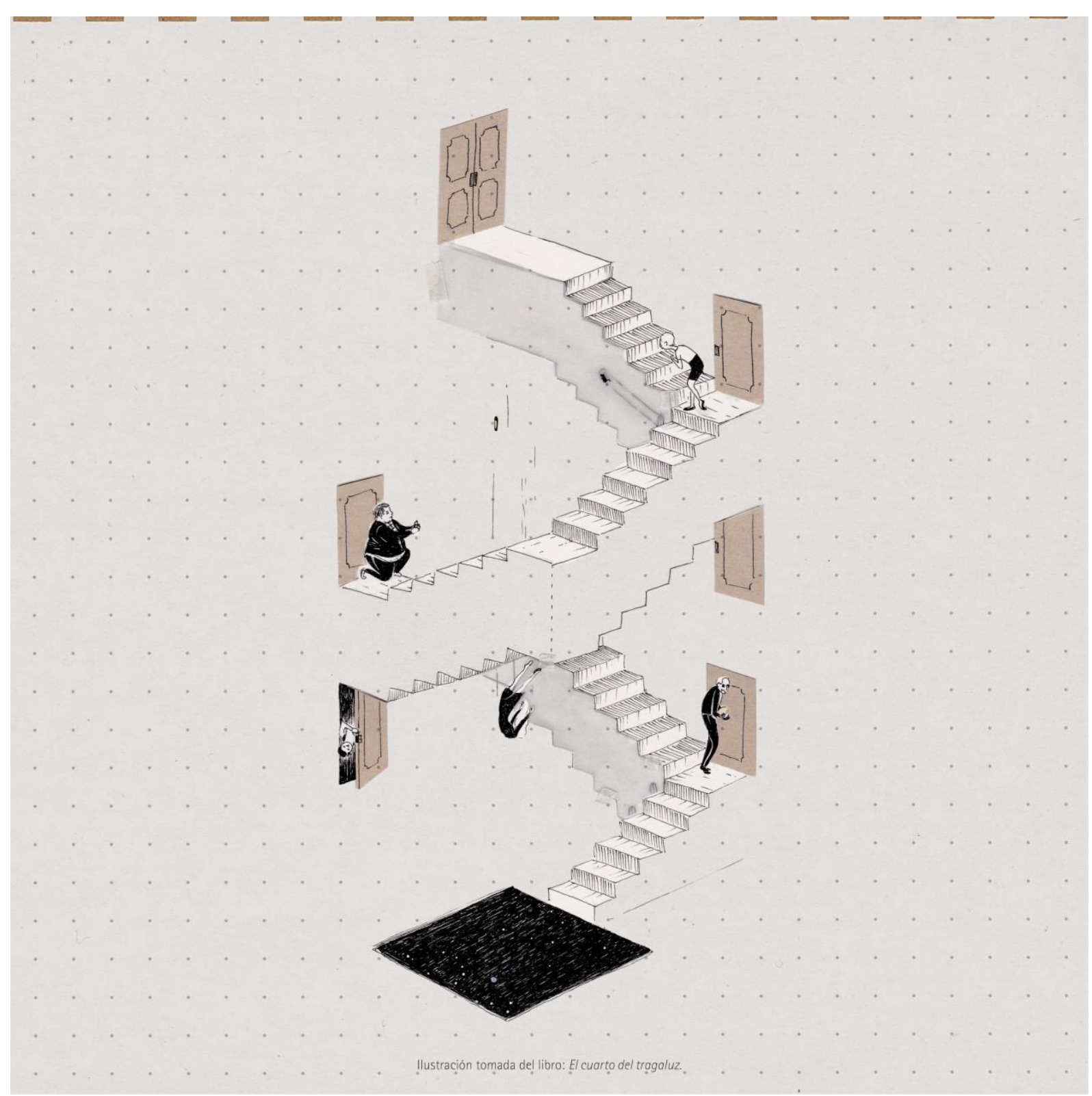

